\title{
Experimental and Numerical Investigation of the Vibration Characteristics in a Cold Rolling Mill Using Multibody Dynamics
}

\author{
Youngdeuk $\mathrm{KIM}^{1)}{ }^{1)}$ Chang-Wan $\mathrm{KIM}^{2)}$ Sung-Jin $\mathrm{LEE}^{3)}$ and Hyunchul PARK ${ }^{1{ }^{* *}}$ \\ 1) Department of Mechanical Engineering, Pohang University of Science and Technology (POSTECH), San31, Hyoja-dong, \\ Nam-gu, Pohang, Kyungbuk, 790-784 Republic of Korea. \\ 2) School of Mechanical Engineering, Konkuk University, 1 Hwayang-dong, Gwangjin-gu, Seoul, 143-701 Republic of Korea \\ 3) Technical Research Laboratories, POSCO, 1, Goedong-dong, Nam-gu, Pohang, Kyungbuk, 790-300 Republic of Korea.
}

(Received on January 28, 2012; accepted on June 13, 2012)

\begin{abstract}
Chatter vibration is detrimental to the quality of the metal strip in the rolling process. A numerical model was proposed to investigate the vibration characteristics. A rolling mill that includes the driving system was modeled by multibody dynamics to investigate the cause and characteristics of the chatter vibration. The proposed numerical model was validated by theoretical analysis and an experiment that was carried out during manufacturing. The frequency of chatter with high amplitude was in the range computed theoretically by the equation for chatter frequency. The range of chatter frequency was very similar to that predicted by the multibody dynamic analysis, if the speed range of the work roll was in steady state. Because the derivative of the chatter frequency was different from that of the gear mesh frequency (GMF), it could be claimed that the frequencies of the chatter and the gear mesh were not related. It was observed in the analysis that the GMF generated by the helical gear was transmitted to the work roll. The amplitudes of the gear mesh and chatter frequencies became high when the rolling force was high, but the chatter frequency did not occur when there was no rolling force. The effects of the speed of the work roll and the ratio between the dynamic and static components of the rolling force to the chatter vibration were also investigated. We found the chatter frequency that affects vibration of the rolling mill strongly, and analyzed the effect of the rolling parameters on chatter frequency.
\end{abstract}

KEY WORDS: cold rolling mill; vibration characteristics; multibody dynamics; rolling force.

\section{Introduction}

Chatter is the phenomenon caused by vibration between the workpiece and the manufacturing machine. Because the chatter reduces the quality of products in the grinding and milling operation, it constitutes a major problem. The chatter vibration of the rolling process also has a significant effect on the surface and thickness of the metal strips.

Chatter vibration is classified into three types: low-frequency forced vibration, third octave gauge and fifth octave. In low-frequency forced vibration, frequencies are usually lower than any of the resonant frequencies of the mill stand and in this case, the vibration is affected by the stiffness of the mill and workpiece being rolled, as demonstrated by Farley et al. ${ }^{1)}$ It is worsened by torsional vibration of the mill. The third octave gauge chatter vibration is caused by excitation of one of the natural resonances of the mill stand. ${ }^{2)}$ It has a natural frequency between 100 and $300 \mathrm{~Hz}$ for the system. In the fifth octave chatter vibration, typical sources may be the forced vibrations from defective gear teeth, roll bearings, drive couplings and a poor surface of the work roll. The chatter frequency is usually in the range 600-

* Corresponding author: E-mail: hcpark@postech.ac.kr DOI: http://dx.doi.org/10.2355/isijinternational.52.2042

\section{$1200 \mathrm{~Hz}$}

Chatter models were formulated by Yun et al. ${ }^{3)}$ to investigate chatter vibration as a consequence of the interaction between the structural dynamics of the mills and the dynamics of the rolling process. Son et al. ${ }^{4)}$ analyzed sources of the mill vibration by measuring the vibration frequency and torque. Defects in the roller bearings of the work roll chock and an oil film bearing in the backup roll chock were presented as sources of vibration. Wu et al. . $^{5}$ analyzed the mechanism of excitation caused by roll bearing structures. They found that the periodic change in the stiffness of the bearings may cause the amplitude and frequency modulation in the vibration of the mill. Self-excited and nonlinear parametric vibration in the cold rolling processes was analyzed by Bar and Swiatoniowski. ${ }^{6}$

Chatter vibration of a cold rolling mill was analyzed using the finite element method to investigate the influence of rolling parameters such as rolling speed, reduction of strip and friction coefficient on chatter vibration, as demonstrated by Mehrabi et al. ${ }^{7)}$ Vibration analysis of the work and backup rolls was performed using a numerical model that assumed that the mill stand and the strip could be analyzed separately because a coupled analysis of strip and rolls is expensive in terms of computational time. ${ }^{8)}$

In this work, we investigated the dynamic behavior of the 
cold rolling mill in the Gwangyang Works of POSCO. For the experimental study, the acceleration of the roll, rolling force and speed of the work roll were measured by accelerometer, load cell and tachometer, respectively. The numerical model of the rolling mill including the driving system was built for multibody dynamic analysis. The model was validated by experiment. The effects of the rolling parameters such as rolling force and speed on chatter vibration were investigated.

\section{Theoretical Background}

The chatter mark is a series of marks made by vibration of the rolls and the strip. If the chatter pitch and line velocity of strip are known, the chatter frequency can be expressed as Eq. (1):

$$
f_{\text {chatter }}=1000 \times V_{l} /\left(60 \times P_{c}\right),
$$

where $V_{l}$ (MPM) is the line velocity of the strip, and $P_{c}$ $(\mathrm{mm})$ is the chatter pitch. $\left.{ }^{9}\right)$ The chatter pitch is the gap between the dark bands, which are a series of marks on the strip caused by vibration of the rolls. Although the chatter mark was very indistinct and it was very difficult to measure exact chatter pitch, the chatter mark on the strip could be observed by grindstone inspection in bright light. The chatter frequency computed by the equation for chatter frequency ranges from 974 to $1461 \mathrm{~Hz}$, considering the chatter pitch $(12 \mathrm{~mm})$ and the range of the rotational speed of the work roll $(8-12 \mathrm{~Hz})$.

The gear mesh frequency (GMF) occurs because of eccentricity of the gear, inappropriate backlash, abrasion of the gear, etc. The gear mesh frequency can be computed as Eq. (2):

$$
(\mathrm{GMF})=Z \times w \times k,
$$

where $Z$ is the number of gear teeth, $w(\mathrm{~Hz})$ is the rotational speed and $k$ is an integer. The GMF was $354.96 \times k \mathrm{~Hz}$ for the model because the gear had 34 teeth and the rotational speed was $10.44 \mathrm{~Hz}$, as measured by an optical sensor in the rolling process.

If the defects of the gear worsen, harmonic components of the GMF occur and the GMF has sidebands of the rotational speed. ${ }^{10)}$ In the case of eccentricity, many sidebands of the rotational speed occur around the GMF. Misalignment of the gear causes frequency of rotation, $(2 \times \mathrm{GMF})$ and $(3 \times$ GMF) with high amplitude. A crack on the gear causes frequency of rotation with high amplitude and the shock wave. If amplitudes of the GMF and the sidebands are high, defects on the gear have to be analyzed.

\section{Experiment}

\subsection{Vibration Measurement of the Rolling Mill}

The cold rolling process is usually conducted with a workpiece that is initially at room temperature. A schematic illustration of the 6-high cold rolling mill is shown in Fig. 1. ${ }^{11)}$ The stands are arranged to produce a sequential reduction in the thickness of the strip. Work rolls are the tools directly in contact with the rolled strip. The intermediate rolls and backup rolls support the work rolls to reduce their deflection under the rolling load. The spindles transmit the torque

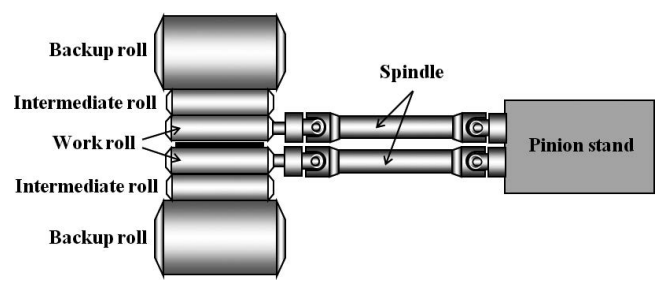

Fig. 1. Schematic illustration of the 6-high cold rolling mill.

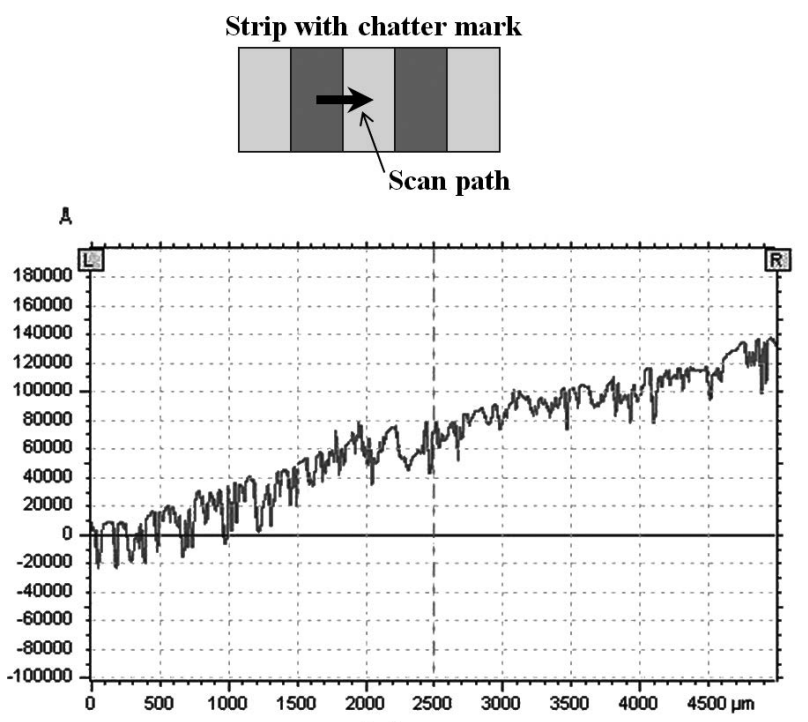

(a)

Strip with chatter mark

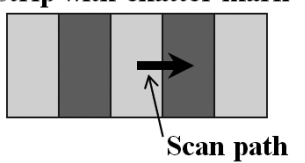

A

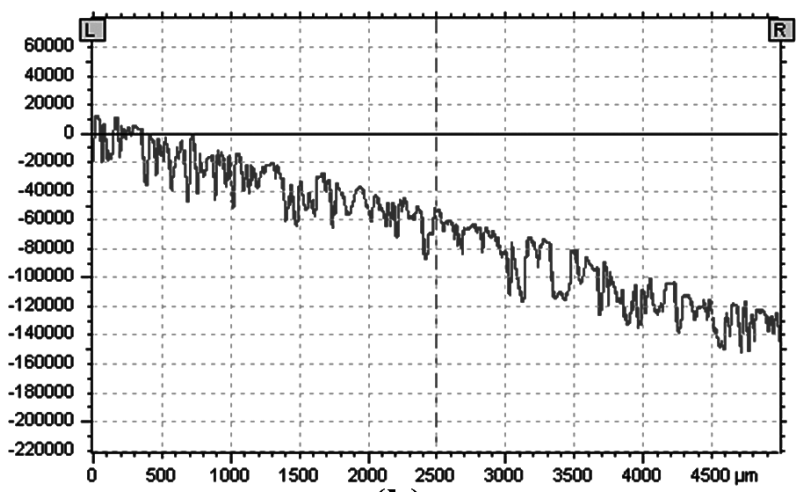

(b)

Fig. 2. Surface profile of the strip with the chatter mark (a) from the dark band to the bright band, and (b) from the bright band to the dark band in the moving direction of the strip.

of the helical gears in the pinion stand into the work roll. ${ }^{12)}$ An accelerometer was installed on the chock of the work roll to measure the vibration acceleration of the work roll. Fast Fourier Transform (FFT) of the acceleration was obtained and analyzed for the vibration characteristic of the work roll. Reflective tape was attached on the surface of the spindle and the speed of the work roll was measured by the tachometer. The rolling force was also measured by the load cell.

\subsection{Surface Profile of the Strip}

The surface profile of the strip that had the chatter mark 
was measured by Alpha-Step IQ Surface Profiler. Figure 2 shows the surface profile of the strip with the chatter mark in the moving direction of the strip. The profile from the dark band to the bright band was upward, as shown in Fig. 2(a), but the profile from the bright band to the dark band was downward, as shown in Fig. 2(b). By comparing the two graphs, it was confirmed that the bright band was convex and the dark band was concave. The chatter mark is the periodic change in thickness of the strip.

\section{Results and Discussion}

\subsection{Validation of the Numerical Model}

A numerical model of the rolling mill including the driving system was built as rigid bodies to perform the multibody dynamic analysis. The static rolling force of the mill was measured and the dynamic rolling force was computed according to the analytical model. Because the 6-high cold rolling mill is structurally symmetrical, only the upper part of the rolling mill was investigated. The work, intermediate and backup rolls were included in the model. Additionally, the helical gears that transmit the torque into the spindle and the spindle that transmits the torque into the work roll were included, as shown in Fig. 3. The spindle consists of three components that are connected by two universal joints. The driving helical gear rotates the driven helical gear. The model took into account transmission of the torque by friction contact between the rolls. Roller bearings that support the axle of helical gears and both ends of the rolls were modeled by spring-damper elements. Gravity was applied to all the components along the negative $z$-direction. Table 1 shows the conditions for the experiment and numerical simulation.

MotionSolve from HyperWorks ${ }^{13)}$ was used for the analysis. The driving helical gear was rotated at the speed of $10.44 \mathrm{~Hz}$ measured by an optical sensor. A rolling force of $10153350 \mathrm{~N}$ measured by the load cell was applied to the work roll. The numerical model was validated by the experimental results. Figure 4 shows the numerical simulation and experiment of the FFT of the work roll for acceleration in the vertical direction. $355 \mathrm{~Hz}$ was the GMF of the helical gear and $1190 \mathrm{~Hz}$ was the chatter frequency of the work roll. The frequency of $1190 \mathrm{~Hz}$ with high amplitude was included in the chatter frequency range of 974 to $1461 \mathrm{~Hz}$, which was previously computed by Eq. (1). The chatter frequency was caused by the vibration of rolls, but the amplitude of the chatter vibration was restricted by the constraints between work roll and spindle in the driving system. It was confirmed that the GMF produced by the helical gear was transmitted to the work roll. The numerical model of the

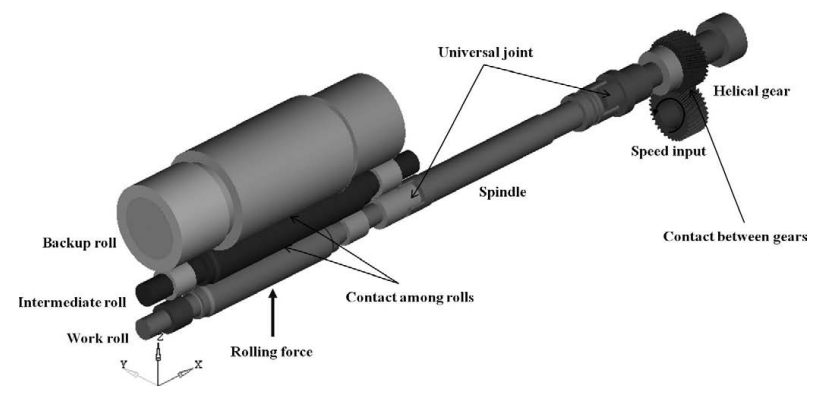

Fig. 3. Numerical model of the cold rolling mill. rolling mill including the driving system, which consists of the spindle and helical gears, was reliable because the numerical simulation was compatible with the experimental result.

Figure 5 shows the FFT numerical simulation of the acceleration of the driven helical gear in the vertical direction. The result indicates not only the first GMF, but also the frequencies of $(2 \times \mathrm{GMF})$ and $(3 \times \mathrm{GMF})$. The chatter frequency of $1190 \mathrm{~Hz}$, which was generated in the work roll,

Table 1. The conditions for the experiment and numerical simulation.

\begin{tabular}{cc}
\hline Parameter & Value \\
\hline Rolling angle, $\alpha\left(^{\circ}\right)$ & 1.81776 \\
Strip thickness at in-gauge, $h_{\text {in }}(\mathrm{mm})$ & 0.934 \\
Strip thickness at out-gauge, $h_{\text {out }}(\mathrm{mm})$ & 0.7 \\
Strip width, w $(\mathrm{mm})$ & 1607.9 \\
Rolling force, $\mathrm{F}_{\mathrm{r}}(\mathrm{N})$ & 10153350 \\
Radius of the work roll, $r_{w}(\mathrm{~mm})$ & 232.5 \\
Radius of the intermediate roll, $r_{i}(\mathrm{~mm})$ & 265 \\
Radius of the backup roll, $r_{b}(\mathrm{~mm})$ & 675 \\
Mass of the work roll, $\mathrm{M}_{\mathrm{w}}(\mathrm{kg})$ & 4583.23 \\
Mass of the intermediate roll, $\mathrm{M}_{\mathrm{i}}(\mathrm{kg})$ & 6104.6 \\
Mass of the backup roll, $\mathrm{M}_{\mathrm{b}}(\mathrm{kg})$ & 31989.92 \\
Friction coefficient between the work roll and \\
strip (affected by rolling oil $), \mu$
\end{tabular}

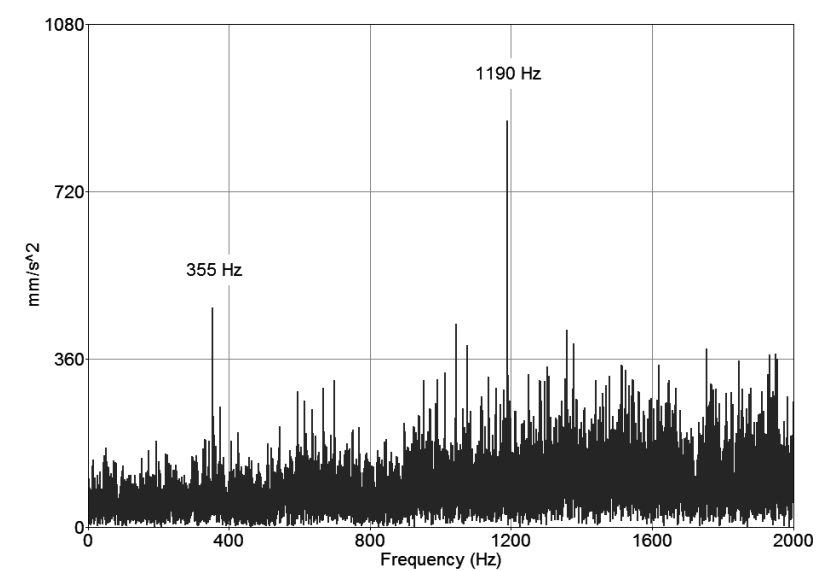

(a)

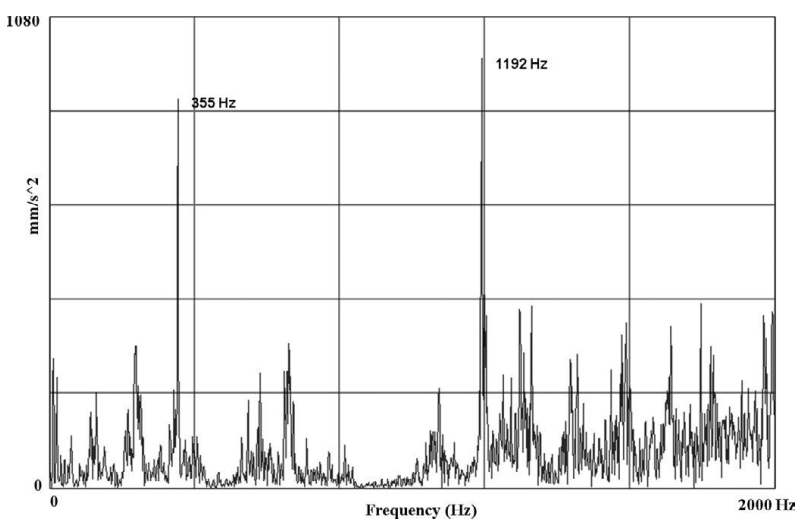

(b)

Fig. 4. FFT of the work roll for acceleration in the cold rolling mill. (a) numerical simulation (b) experiment. 
did not appear; therefore, it was not related to the helical gear. We confirmed that the GMF generated by the helical gear was transmitted to the work roll through the spindle, but the amplitude decreased because the amplitude of the first GMF of the driven helical gear was very high compared with that of the work roll.

\subsection{Parametric Analysis of the Numerical Model}

Figure 6 shows numerical simulation of the FFT of the work roll acceleration with varying rolling force. When no rolling force was applied to the work roll, it did not generate the frequency of $1190 \mathrm{~Hz}$, but low amplitudes were obtained at GMFs of $355 \mathrm{~Hz}$ and $(2 \times 355 \mathrm{~Hz})$ (Fig. 6(a)). When a rolling force was applied to the work roll, it generated not only the GMF but also chatter frequency of 1190 $\mathrm{Hz}$, which indicated that this chatter frequency was caused by the rolling force. As the rolling force increased, the amplitude of GMF and the chatter frequency also increased. There is no direct experimental data related to the numerical

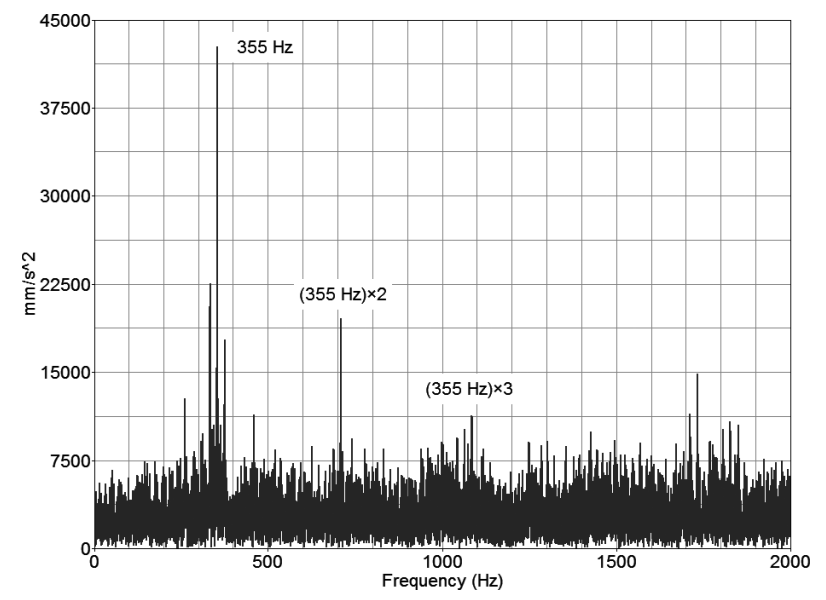

Fig. 5. FFT of the acceleration of the driven helical gear.
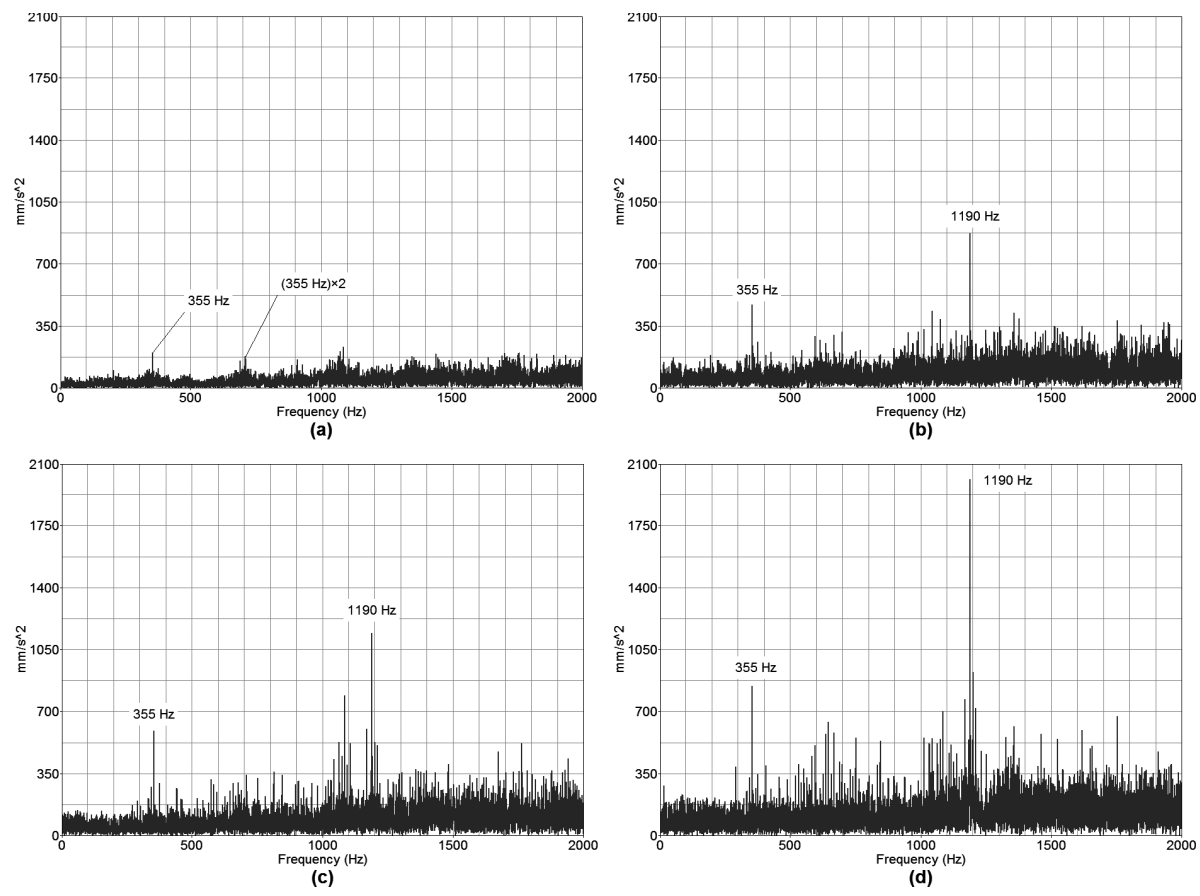

Fig. 6. FFT of the work roll acceleration with (a) no rolling force, (b) $10153350 \mathrm{~N}$ rolling force, (c) 20000000 rolling force and (d) $30000000 \mathrm{~N}$ rolling force.

analysis in this paper because the rolling force was fixed during the manufacturing process. But the phenomenon that the amplitude of the chatter frequency increased with the rolling force was generally well known. The phenomenon was well explained by the verified numerical model.

The rotational speed of the work roll ranged from 8 to 12 $\mathrm{Hz}$ in the steady state. To investigate the effect of rotational speed, the driving helical gear was rotated at varying speeds in numerical simulation. Figure 7 shows numerical simulation of the FFT of the work roll acceleration at different rotational speeds. The gear mesh frequency was $272 \mathrm{~Hz}$ at the rotational speed of $8 \mathrm{~Hz}$ because the number of gear teeth was 34. There are the GMF of $272 \mathrm{~Hz}$ and the chatter frequency of $912 \mathrm{~Hz}$, as shown in Fig. 7(a). Figure 7(b) shows the numerical simulation for the rotational speed of $12 \mathrm{~Hz}$, in which GMF was $408 \mathrm{~Hz}$ and chatter frequency was $1368 \mathrm{~Hz}$. Thus, the chatter frequency ranged from 912 to $1368 \mathrm{~Hz}$, if the speed range of the work roll in steady state was considered. As the rotational speed increased, the amplitudes of the gear mesh and the chatter frequency also increased, as shown in Figs. 4(a) and 7.

Figure 8 shows the relationship between the rotational speed and frequency. GMF and the chatter frequency are proportional to the rotational speed. Because GMF can be computed by Eq. (2), the derivative is dependent on the number of gear teeth. The chatter vibration was not related to the driving system because the derivative of the chatter frequency was different from that of the GMF in the relationship between the rotational speed and frequency. When no rolling force was applied to the work roll, the chatter frequency was not generated. Therefore, the chatter vibration was the vibration of the rolls caused by contact stiffness between rolls when the rolling force was applied. As the speed of the work roll and the rolling force increased, the amplitude of the chatter frequency also increased.

The vibration of the rolling mill and strip has generated 


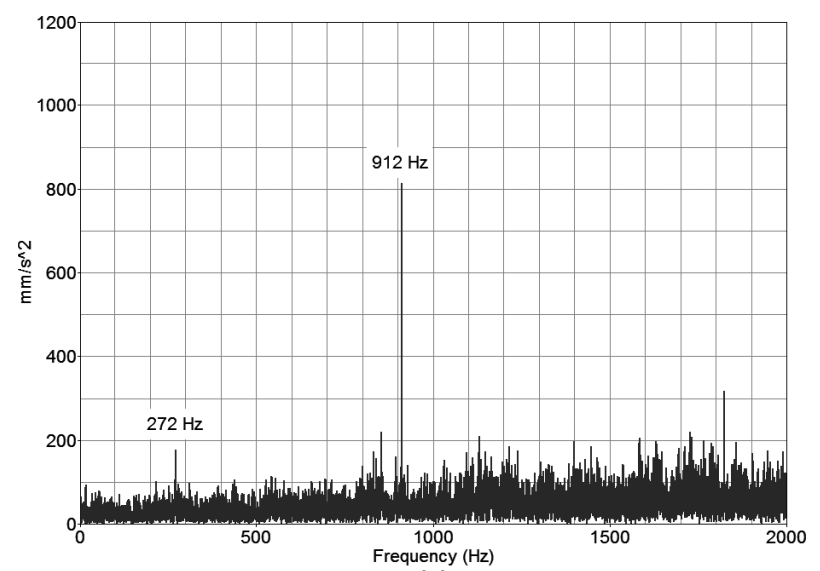

(a)

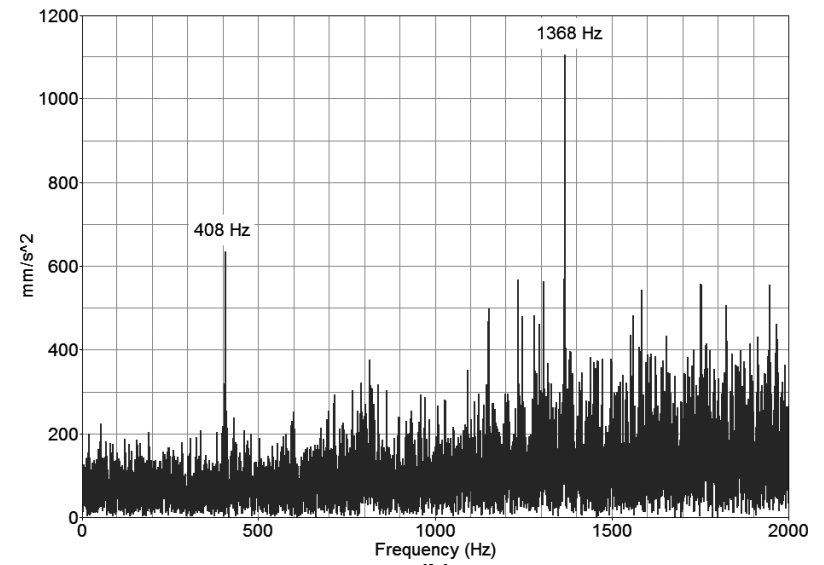

(b)

Fig. 7. FFT of the work roll acceleration at the rotational speeds of (a) $8 \mathrm{~Hz}$ and (b) $12 \mathrm{~Hz}$.

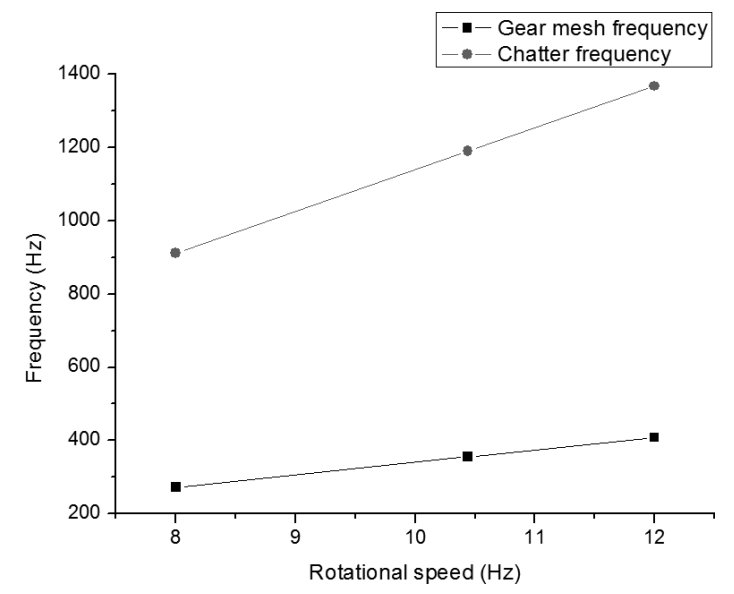

Fig. 8. Relationship between the rotational speed and frequency.

a dynamic component of the rolling force. Thus, the rolling force can be expressed as the sum of the static and dynamic components. The latter component can be computed according to the analytical model demonstrated by Swiatoniowski and Bar. ${ }^{14)}$ The reaction force of the strip being rolled can be described using the relationship as Eq. (3):

$$
P=\left(K-\sigma_{m}\right) d \sqrt{R \Delta h},
$$

where $K$ is the yield stress for the unidirectional compressive test, $\sigma_{m}$ is the average value of stress applied on the strip, $d$ is the average width of the strip, $R$ is roll radius and $\Delta h$ is the change in the strip thickness between the inlet and

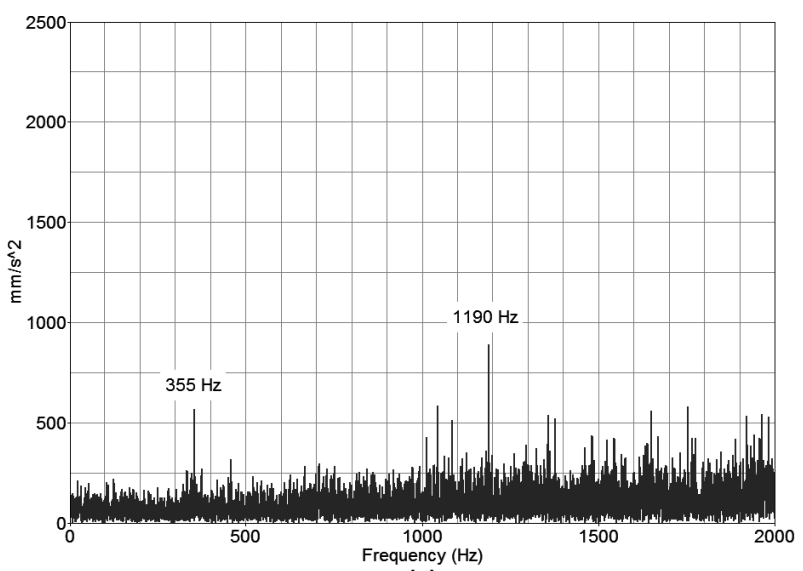

(a)

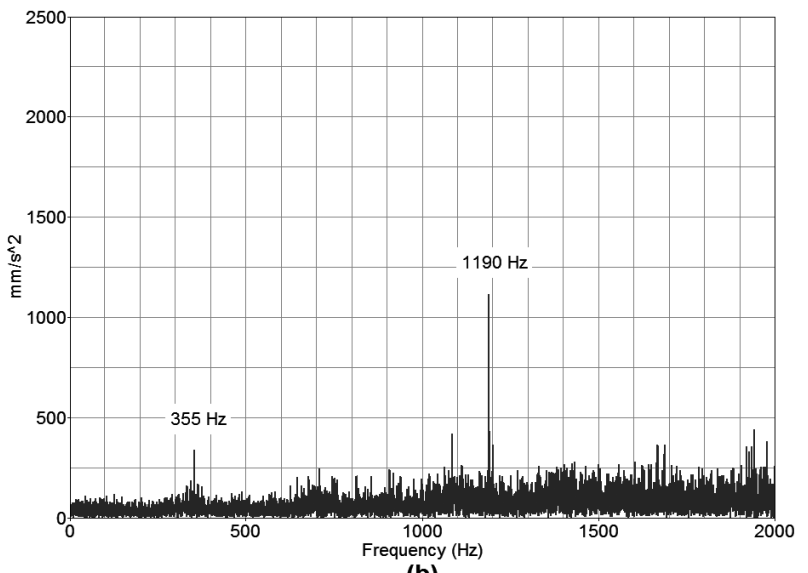

(b)

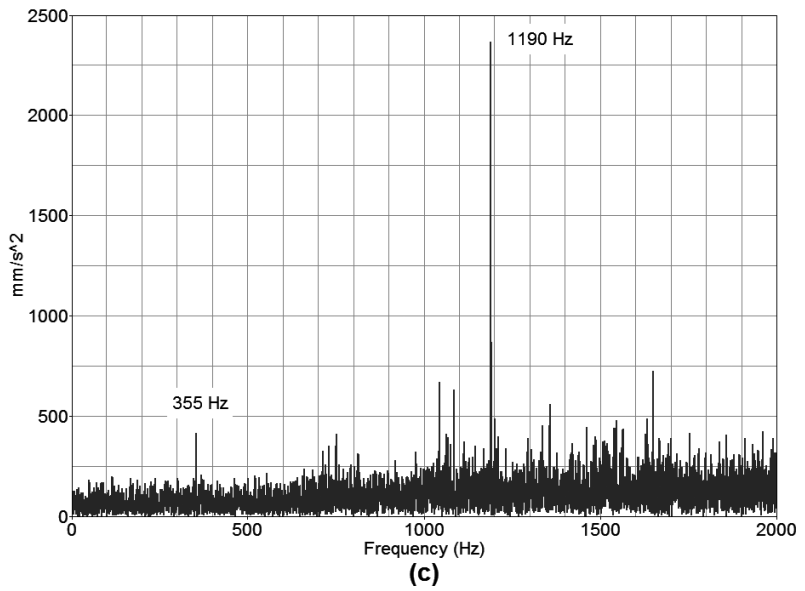

Fig. 9. FFT of the work roll acceleration with the rolling force including the static and dynamic components in which amplitudes of the dynamic component are (a) $0.01 \%$, (b) $0.1 \%$ and (c) $1 \%$ of the static component.

the outlet of the rolling stand. The dynamic component can be expressed as Eq. (4):

$$
P_{d}=\left(K-\sigma_{m}\right) d\{\sqrt{R(\Delta h+2 y)}-\sqrt{R \Delta h}\},
$$

where $y$ is the vertical displacement of the work roll, which is assumed to be periodic and can be expressed as Eq. (5):

$$
y=A \sin \left(\omega_{k} t+\varphi_{0}\right),
$$

where $\omega_{k}$ is the critical angular speed corresponding to the frequency of resonance of the mill stand, $t$ is the time and $\varphi_{0}$ is the phase angle. Coefficient A affects only the amplitude of the dynamic component. Figure 9 shows the numerical simulation of the FFT of the work roll acceleration with 
the rolling force including the static and dynamic components in which amplitudes of the dynamic component are $0.01 \%, 0.1 \%$ and $1 \%$ of the static component. When the amplitude of the dynamic component was $0.01 \%$ of the static component, the amplitude of the chatter frequency of $1190 \mathrm{~Hz}$ was very similar to the case when only the static component of the rolling force was applied. In this case, the amplitude of the dynamic component was so low that the dynamic component did not affect the chatter frequency. When the dynamic component was $0.1 \%$ of the static component, the amplitude of chatter frequency of $1190 \mathrm{~Hz}$ increased, as shown in Fig. 9(b). When the dynamic component was $1 \%$ of the static component, the amplitude of the chatter frequency of $1190 \mathrm{~Hz}$ became very high, as shown in Fig. 9(c). Although the dynamic component was very small, $0.1 \%$ of the static component, it could affect the amplitude of the chatter frequency. The dynamic component had to be decreased to reduce chatter vibration.

\section{Conclusion}

The dynamic behavior of a cold rolling mill that includes the driving system was investigated by multibody dynamics. The proposed numerical model was validated by theoretical analysis and experiment. The chatter frequency was 1190 $\mathrm{Hz}$ by numerical simulation and experiment, which is within the range 974-1 $461 \mathrm{~Hz}$ predicted by the theory. The range predicted by the theory was very similar to that predicted by the multibody dynamic analysis, which ranges from 912 to $1368 \mathrm{~Hz}$. A GMF of $355 \mathrm{~Hz}$ generated by the helical gear was transmitted to the work roll through the spindle.

When no rolling force was applied to the work roll, the chatter frequency was not generated, but GMFs were generated. However, when a rolling force was applied to the work roll, it generated high amplitudes not only for the GMF but also for the chatter frequency, which means that the chatter frequency was caused by the rolling force. As the rolling force increased, the amplitude of the chatter frequency and GMF also increased. The chatter frequency was not related to the GMF, because the derivative of the chatter frequency was different from that of the GMF.
As the speed of the work roll and the dynamic component of the rolling force increased, the amplitude of the chatter frequency also increased. Although the dynamic component was very small compared with the static component, it could strongly affect the chatter frequency. It was confirmed that the amplitude of chatter vibration could be reduced by controlling the speed of the roll, and the static and dynamic components of the rolling force.

\section{Acknowledgements}

This research was supported by the POSCO Research Project (2009Y215) from POSCO Technical Research Laboratories. This research was also supported by Basic Science Research Program through the National Research Foundation of Korea (NRF) funded by the Ministry of Education, Science and Technology (grant number 20090077217 and 2009-0067895)

\section{REFERENCES}

1) T. W. D. Farley, S. Rogers and D. Nardini: Proc. of the Conf., Vibration in Rolling Mills, Institute of Materials, London, (2006).

2) T. W. D. Farley, D. Nardini, S. Rogers and D. S. Wright: Proc. of TMS 2002, 131st Annual Int. Meeting, TMS, Warrendale, PA, USA, (2002).

3) I. S. Yun, W. R. D. Wilson and K. F. Ehmann: Int. J. Mach. Tools Manuf., 38 (1998), 1499.

4) B. Son, Y. Roh and Y. Lee: Korean. Soc. Noise Vib. Eng., 4 (1994), 43.

5) Y. X. Wu and J. A. Duan: J. Mater. Process. Technol., 129 (2002), 148 .

6) A. Bar and A. Swiatoniowski: J. Mater. Process. Technol., 155-156 (2004), 2116.

7) R. Mehrabi, M. Silani, S. Ziaei-Rad, M. Salimi and A. Kamranian: Metal Forming, 1 (2008), 467.

8) E. Brusa and L. Lemma: J. Mater. Process. Technol., 209 (2009), 2436.

9) C. Lee: Master's thesis, Graduate School of Iron \& Steel Technology, Pohang University of Science and Technology, (1999), 6.

10) H. Jun, J. Lee and S. Lee: J. Korean. Soc. Mech. Eng., 35 (1995), 414.

11) V. B. Ginzburg and R. Ballas: Flat Rolling Fundamentals, Marcel Dekker, New York, USA, (2000), 381.

12) W. L. Roberts: Cold Rolling of Steel, Manufacturing Engineering and Materials Processing, 2, CRC Press, New York, USA, (1978), 64.

13) HyperWorks 9.0, MotionView Introduction, HyperWorks 9.0 Release, Altair Engineering Inc., Troy, Mich. USA, (2009), 1.

14) A. Swiatoniowski and A. Bar: J. Mater. Process. Technol., 134 (2003), 214. 